\title{
parental treatment methods and its relationship to academic achievement motivation among a sample of high school students ALardeat
}

\author{
Ashraf Ali Saeed. Abdou and Nawaf Abdul Rahim al-Amiri \\ Faculty of Education, South Valley University
}

\begin{abstract}
:
The study aimed to identify the degree of prevalence of parental treatment methods and the level of prevalence of achievement motivation among secondary school students ALardeat province, and the disclosure of the relationship between parental treatment methods and the prevalence of achievement motivation, detecting statistical differences between the mean scores of students Mrtfie motivation academic achievement and grades low student motivation academic achievement in their grades on parental treatment methods, detection of significance statistical differences in parental treatment methods and the motivation of academic achievement depending on the specialty and grade, and to achieve the objectives of the study were used parental treatment methods scale (Qarni 0.2016) ، was used as achievement motivation prepared by Omari in scale ( $2012 \mathrm{~m}$ ، ( the study sample consisted of (447) students were chosen randomly Statistics, moderate degree in parental treatment methods where all the tactics appeared moderately Independence / high dependency. And it was arranged (Independence- reliance, dependability Independence- democratic - autocratic, tolerance.
\end{abstract}

Keywords: Gentle Transaction methods; Achievement motivation

Citation: Abdou and al-Amiri Requirements of Electronic Management in the Management of Kindergarten Institutions. SVU-Journal of abstract 2019, Vol.1: pp23 (retrieved from the Journal of Educational Sciences; 2018, No.35; pp 258).

Copyright: Publiser South Valley University. This is an open-access article distributed under the terms of the creative commons attribution license, which permits unrestricted use, distribution and reproduction in any medium provided the original author and source are created. 